\title{
The effects of the fibre content and physical structure of carrots on satiety and subsequent intakes when eaten as part of a mixed meal
}

\author{
S. Anne Moorhead ${ }^{1}$, Robert W. Welch ${ }^{1}$, M. Barbara ${ }^{1}$, E. Livingstone ${ }^{1}$, Maeve McCourt ${ }^{1}$, Amy A. Burns ${ }^{2}$ \\ and Adrian Dunne ${ }^{3}$ \\ ${ }^{1}$ Northern Ireland Centre for Food and Health, School of Biomedical Sciences, University of Ulster, Coleraine BT52 1SA, UK \\ ${ }^{2}$ School of Hotel, Leisure and Tourism, University of Ulster, Portrush BT56 8JL, UK \\ ${ }^{3}$ Statistics Department, University College Dublin, Belfield, Dublin 4, Republic of Ireland
}

(Received 21 June 2005 - Revised 6 January 2006 - Accepted 27 February 2006)

\begin{abstract}
Previous research indicates that vegetables yield relatively high satiety scores, and that fibre content and structure may both contribute to these effects. This study evaluated the effects of the fibre content and physical structure (gross anatomy and cell structure) of carrots on postprandial satiety and subsequent food intakes when consumed as part of a mixed meal. Using a randomised, repeated-measures, within-subject cross-over design, young women consumed a standardised breakfast and test lunches on three occasions, 4 weeks apart. The test lunches ( $3329 \mathrm{~kJ})$ comprised boiled rice (200 g) with sweet and sour sauce (200 g) that included chicken $(200 \mathrm{~g})$ and carrots $(200 \mathrm{~g})$ in three conditions: whole carrots (fibre and structure; $n$ 34), blended carrots (fibre but no structure; $n$ 34) or carrot nutrients (no fibre or structure; $n$ 32). The carrot nutrients had the same energy, major nutrients and portion weight as the other two conditions. Post-lunch satiety was assessed by visual analogue scales. Intakes were covertly weighed at a meal eaten ad libitum ( $3 \mathrm{~h}$ later), and for the remainder of the day using food diaries. Compared with the meal with carrot nutrients, meals with whole carrots and blended carrots resulted in significantly $(P<0 \cdot 05)$ higher satiety. There were significant $(P<0 \cdot 05)$ differences between conditions in intakes at the meal eaten ad libitum and for the remainder of the day, and intakes consistently decreased in the order: carrot nutrients, blended carrots, whole carrots, indicating that both fibre content and structure played a role in these effects.
\end{abstract}

Satiety: Energy intake: Carrots: Fibre: Food structure

Dietary guidelines for health recommend increased fruit and vegetable consumption (Department of Health, 1997; United States Department of Health and Human Services and United States Department of Agriculture, 2005). Fruits and vegetables generally have a low energy density and may help to combat overweight and obesity by limiting the consumption of other, more energy-dense foods (Astrup et al. 2004; Rolls et al. 2004). Furthermore, fruits and vegetables provide micronutrients, non-nutrient phytochemicals and dietary fibre that may contribute to health benefits.

A number of studies have shown that dietary fibre can increase satiety and decrease energy intake (Howarth et al. 2001). Relatively few studies have, however, evaluated the effects of fruits or vegetables on satiety (Rolls et al. 2004). A comparison of the effects on satiety of isoenergetic $(1000 \mathrm{~kJ})$ portions of a wide range of foods ( $n$ 38) showed that boiled potatoes gave the highest satiety scores, and that scores were also high for fruits (Holt et al. 1995). Overall, there was a significant positive correlation between satiety scores and fibre contents, but the predictability was low $\left(r^{2} 0 \cdot 21\right)$. The strongest correlations were found between satiety and serving size $\left(r^{2} 0.44\right)$ and satiety and water content $\left(r^{2} 0 \cdot 41\right)$, suggesting that these factors might be more important than fibre content per se (Holt et al. 1995).

When eaten in a mixed meal setting, a variety of vegetables (carrots, peas, Brussel sprouts, spinach) in portion sizes of 96-164 $\mathrm{g}$ had no significant effects on satiety (Gustafsson et al. 1993). Satiety was, however, significantly increased when the carrot portion size was 200 or $300 \mathrm{~g}$ (Gustafsson et al. 1994). These mixed meals were balanced for energy and macronutrients, but, at the higher carrot portion sizes, total meal weights were $86 \%$ and $130 \%$ greater than the controls. In view of the relatively strong correlation between serving size and satiety (Holt et al. 1995), and the increasing evidence that meal weight is a strong determinant of satiety even when energy and macronutrients are held constant (Rolls et al. 1998, 1999), the greater meal weights are likely to have contributed to the effects of the carrots on satiety.

Earlier work with apples, oranges and grapes consumed as fruit pieces, following physical disruption (purée), or following physical disruption and fibre removal (juice), showed that both physical structure and fibre content contributed to increased satiety (Haber et al. 1977; Bolton et al. 1981). 
In those studies, however, the test meals were given at breakfast, and subsequent intakes were not assessed.

The present study extends this work to carrots presented in a typical mixed lunch meal that comprised chicken, sweet and sour sauce, boiled rice and carrots served in three conditions: whole carrots (fibre and structure), blended carrots (fibre but no structure) or carrot nutrients (no fibre or structure). In addition to assessment of subjective satiety, intakes were measured for the rest of the day. On the basis of previous results, we hypothesised that both the physical structure (gross anatomy and cell structure) of carrots and the carrot fibre would impact on postprandial satiety and subsequent food intakes when consumed as part of a mixed meal.

\section{Materials and methods}

\section{Study design}

The study was a randomised, repeated-measures, within-subject cross-over design, carried out with non-obese women (BMI less than $30 \mathrm{~kg} / \mathrm{m}^{2}$ ). Each subject was studied on three occasions on the same day of the week with a 4-week interval between crossover to minimise potential effects caused by phase of the menstrual cycle. On each occasion, subjects consumed a standardised breakfast that provided $25 \%$ of their estimated energy requirement, lunch (the carrot meal) and an afternoon meal eaten ad libitum. Postprandial satiety was measured subjectively using visual analogue scales (VAS) following the lunch meal. Food intake was assessed at the afternoon meal eaten ad libitum by covert weighing, and for the remainder of the day by food diaries. The study was approved by the Research Ethical Committee of the University of Ulster and all subjects gave informed consent.

\section{Subjects}

We recruited thirty-six women from the administrative and technical staff at the University of Ulster. Potential subjects were interviewed, and the following inclusion criteria were used: aged 20-40 years; BMI $20 \cdot 0-29.9 \mathrm{~kg} / \mathrm{m}^{2}$; non-smokers; liking for all the foods to be used in the study; no known food allergies or restrictions; not on a specific diet; not taking any medications known to affect appetite; not taking oral contraceptives; regularly menstruating; not pregnant or lactating; generally healthy.

At enrolment, subjects gave the date of the start of their last menstruation, and were assigned to six groups of six persons each so that subjects were at similar points in their menstrual cycle on each study day, i.e. days 4-10, when food intake is reportedly most stable (Lissner et al. 1988). The order in which the conditions were presented was counterbalanced between groups. Subjects completed the Dutch Eating Behaviour Questionnaire, which gives a measure of restrained, emotional and external eating (van Strien et al. 1986). Weight and height were measured to calculate the BMI $\left(\mathrm{kg} / \mathrm{m}^{2}\right)$. Estimated daily energy requirements were calculated as 1.4 times estimated BMR (Schofield, 1985).

\section{Procedures}

All meals were served in the metabolic suite of the university, and the subjects were free to leave after each meal to continue normal activities. We asked the subjects to fast from 22.00 hours the previous day and to arrive at 9.00 hours in a fasting state. On arrival, compliance was confirmed, and the subjects consumed breakfast and left the metabolic suite. Subjects returned at 12.30 hours, and completed the VAS, following which lunch was served and time-to-eat was covertly recorded. After lunch, the subjects completed the VAS and left the metabolic suite with instructions to complete the VAS every $45 \mathrm{~min}$ until the afternoon meal (16.00 hours). Pre-set timers were provided to remind the subjects to complete the VAS at the appropriate times. Subjects returned to the metabolic suite at 16.00 hours, completed their final VAS and were provided with an afternoon meal eaten ad libitum. After this, subjects were given food diaries to complete (description of food, brand name if appropriate, estimated portions and leftovers) for the remainder of the day.

Subjects were provided with bottled water (1 litre) for consumption ad libitum after breakfast and lunch, and intakes were assessed by weighing. Subjects were asked not to eat or drink anything except the food and beverages provided until after the afternoon meal and to refrain from strenuous physical activity.

\section{Test meals}

All foods were purchased from local supermarkets. Breakfast, which provided $25 \%$ of each subject's estimated energy intake, consisted of ready-to-eat cereal with milk, toast with butter or margarine and preserve, served with coffee or tea (with milk and sugar if desired). Subjects made breakfast choices before the commencement of the study, and the same breakfast, in terms of both foods and amounts, was given on each occasion.

Lunch was a mixed meal of boiled rice $(200 \mathrm{~g})$ with sweet and sour sauce $(200 \mathrm{~g})$ that included chicken $(200 \mathrm{~g})$ and carrots $(200 \mathrm{~g})$ in three conditions. These conditions were: whole carrots (fibre and structure); blended carrots (fibre but no structure); carrot nutrients (no fibre or structure). Prior to the study, six young women (not in the main study) assessed the lunch meals for palatability and portion size, and all found the meals to be acceptable. Meals were cooked in bulk in a catering kitchen. Frozen baby carrots were steamed at $100^{\circ} \mathrm{C}$ for $12 \mathrm{~min}$. After cooling, the carrots for the blended carrot condition were put through a blender (Robot Coupe R20); Robot Coupe (UK) Ltd., Isleworth, UK) at $3000 \mathrm{rpm}$ for $1 \mathrm{~min}$. The chicken breasts were diced and fried in sunflower oil. The sweet and sour sauce consisted of water, apple juice, white granulated sugar, tomato purée, mango chutney, wine vinegar, cornflour and a chicken stock cube.

Preparation of the carrot nutrients by removal of fibre was impracticable, and the carrot nutrient condition was formulated from food ingredients to give the same energy, major nutrients and portion weight as the whole or blended carrots. To achieve this, a sample of the carrots was analysed for macronutrients, dietary fibre, $\mathrm{Na}, \mathrm{K}$ and $\mathrm{Ca}$ (Reading Scientific Services Ltd, Reading, UK), and carrot nutrients were prepared in bulk containing the same nutrients as the carrots but with no dietary fibre. Each portion of carrot nutrients contained $9.2 \mathrm{~g}$ granulated sugar, $5.2 \mathrm{~g}$ cornflour $(4.8 \mathrm{~g}$ starch), $2.25 \mathrm{~g}$ dried egg white ( $1.8 \mathrm{~g}$ protein; Finlay, Moira, UK), $665 \mathrm{mg} \mathrm{KCl}$ (food grade; $348 \mathrm{mg} \mathrm{K}$; Klinge Chemicals Ltd, 
East Kilbride, UK), $600 \mathrm{mg}$ safflower oil (600 mg fat), $211 \mathrm{mg}$ salt $\left(82 \mathrm{mg} \mathrm{Na}\right.$ ) and $125 \mathrm{mg} \mathrm{CaCl}_{2}$ (food grade; $46 \mathrm{mg} \mathrm{Ca}$; Ellis \& Everard Ltd, Pontefract, West Yorkshire, UK) made up to $200 \mathrm{~g}$ with water.

The energy and nutrient contents of the total lunch, carrots and carrot nutrients are shown in Table 1. All meals had the same energy, macronutrient, $\mathrm{Na}, \mathrm{K}, \mathrm{Ca}$ and water contents, and the same weight and volume. The chicken, sweet and sour sauce, and whole or blended carrots, or carrot nutrients, were portioned together, blast-frozen and stored at $-20^{\circ} \mathrm{C}$.

On each study day, portions were placed in serving bowls, defrosted and reheated in a microwave oven. Preliminary experiments showed that $83 \mathrm{~g}$ uncooked rice yielded $200 \mathrm{~g}$ cooked rice. Consequently, $83 \mathrm{~g}$ portions of uncooked rice were boiled in boiling bags ( $12 \mathrm{~min}$; unsalted water). The $200 \mathrm{~g}$ rice was served on a plate with a separate bowl containing the other meal components of chicken $(200 \mathrm{~g})$, sweet and sour sauce $(200 \mathrm{~g})$ and carrots or carrot nutrients $(200 \mathrm{~g})$, which were completely mixed together. Thus, for all conditions, the chicken was suspended in the sauce; for the carrot nutrient and blended carrot conditions, the carrots formed part of the sauce; and for the whole-carrot condition, the carrots were suspended in the sauce. Subjects were asked to consume the complete meal with $200 \mathrm{ml}$ bottled water. No condiments were provided.

The afternoon meal was a buffet style meal taken ad libitum. Before the start of the study, the subjects were asked to choose two sandwich fillings from the range of ham, tuna, tomato, cheese and salad (lettuce, tomato, cucumber, salad cream). Sandwiches were presented with a choice of tea or coffee and/or a soft drink. The other food items in the buffet were: salad ( $20 \mathrm{~g}$ lettuce, $20 \mathrm{~g}$ tomato, $16 \mathrm{~g}$ cucumber, $10 \mathrm{~g}$ cheese); four chicken bites $(40 \mathrm{~g})$; four cocktail sausage rolls $(56 \mathrm{~g})$; two sachets of sauces $(20 \mathrm{~g})$; two cake bars (chocolate and plain; $70 \mathrm{~g})$; two chocolate biscuits $(30 \mathrm{~g})$; potato crisps (35g); fruit salad $(150 \mathrm{~g})$. Depending upon menu choices, the total buffet provided 6531-12954kJ energy, $32-58 \mathrm{~g}$ protein, $68-102 \mathrm{~g}$ fat and $206-223 \mathrm{~g}$ carbohydrate. The energy and macronutrient content of all meals were calculated using manufacturers' or food table data (Food Standards Agency, 2002a).

\section{Assessment of satiety, hedonic and sensory factors}

Satiety, hedonic and sensory factors were assessed using the VAS by the pen and paper method (Green \& Blundell, 1996). Each scale consisted of a plain $100 \mathrm{~mm}$ horizontal line preceded by a question and with anchors at each end. Subjects were required to put a single vertical mark at the appropriate point that described their feelings at that time. The questions and left and right anchors were 'How hungry do you feel?' (hunger), 'not hungry at all', 'as hungry as I have ever felt'; 'How full do you feel?' (fullness), 'not full at all', 'as full as I have ever felt'; 'How strong is your desire to eat?' (desire to eat), 'very weak', 'very strong'; 'How much food do you think you could eat?' (prospective consumption), 'nothing at all', 'a large amount'; 'How thirsty are you?' (thirst), 'not thirsty at all', 'as thirsty as I have ever felt'.

Immediately after the lunch meal, subjects also completed VAS with the questions and anchors: 'What do you think about the size of your meal?' (size), 'extremely small', 'extremely large'; 'What was the consistency of the meal?' (thickness), 'not thick at all', 'extremely thick'; 'How sweet was the meal?' (sweetness), 'not sweet at all', 'extremely sweet'; 'How pleasant was the meal?' (pleasantness), 'not pleasant at all', 'extremely pleasant', and 'How much have you enjoyed the meal?' (enjoyment), 'not enjoyed at all', 'extremely enjoyable'.

\section{Intake assessments}

Following the afternoon meal eaten ad libitum, individual leftovers were weighed to the nearest $0 \cdot 1 \mathrm{~g}$, and food intakes were calculated by difference. The estimated portion sizes from the subjects' food diaries for the remainder of the day were converted to weights using manufacturers' data or standard portion sizes (Food Standards Agency, 2002b), and the weights of food and drink were calculated. Energy, macronutrient and fibre intakes from the afternoon meal and from the food diaries, and alcohol consumption from the food diaries were calculated using a dietary analysis program (Wisp version 2.0; Tinuviel Software, Warrington, UK). The amount of water in food and drink was calculated from food table data (Food Standards Agency, 2002a), using Microsoft Excel (version 2000;

Table 1. Energy and nutrient contents of the total lunch, carrots and carrot nutrients*

\begin{tabular}{lccc}
\hline & Total lunch $(800 \mathrm{~g})$ & Carrots or carrot nutrients $(200 \mathrm{~g})$ & \% from carrots \\
\hline Energy $(\mathrm{kJ})$ & 3329 & 277 & 8.3 \\
Protein $(\mathrm{g})$ & 51.8 & 1.8 & 3.5 \\
Fat $(\mathrm{g})$ & 10.4 & 0.6 & 5.8 \\
Total carbohydrate $(\mathrm{g})$ & 129.0 & 14.0 & 10.9 \\
$\quad$ Sugars $(\mathrm{g})$ & 53.8 & 9.2 & 17.1 \\
Starch $(\mathrm{g})$ & 75.2 & 4.8 & 6.4 \\
Fibre $(\mathrm{g})$ & $4.8 \dagger$ & $4.4 \ddagger$ & 91.7 \\
& $0.4 \S$ & $0.0 \|$ & \\
Water $(\mathrm{g})$ & 703.0 & 181.0 & 25.7 \\
Na $(\mathrm{mg})$ & 902.0 & 82.0 & 9.1 \\
$\mathrm{~K}(\mathrm{mg})$ & 1550.0 & 348.0 & 22.5 \\
Ca $(\mathrm{mg})$ & 130.0 & 46.0 & 35.4 \\
\hline
\end{tabular}

* Data for carrots from laboratory analysis; other data from suppliers or food tables.

† Lunches with whole or blended carrots.

Whole or blended carrots.

$\S$ Lunches with carrot nutrients.

\| Carrot nutrients.

For details of diets and procedures, see p. 588. 
Microsoft Corporation, Redmond, WA, USA). Total energy intakes for each day were calculated. Energy intakes at the lunches and for the total day were calculated as percentages of estimated daily energy intakes for each subject.

\section{Laboratory evaluations}

In order to assess the degree of disruption of the blended carrots, duplicate droplets were stained with toluidine blue using Gurrs mounting medium, and observed by phase-contrast and bright-field imaging. Six fields of the sample images were recorded using an Eclipse 400 microscope (Nikon UK Ltd, Kingston-upon-Thames, UK) with a 100:1 oil-immersion lens (numerical aperture 1.3) and total magnification of $\times 1000$.

Other food factors (osmolality, $\mathrm{pH}$, buffering capacity) that might influence gastric function and impact on satiety and intake (Bolton et al. 1981; Tadesse, 1986; Liljeberg \& Björck, 1996) were assessed as follows. The water activity (a proxy for osmolality) and the $\mathrm{pH}$ of the blended carrots in sweet and sour sauce and carrot nutrients in sweet and sour sauce were measured in duplicate using a water activity meter (Durotherm; Lufft GmbH, Fellbach, Germany) and a pH meter (Corning M20; Corning, Sudbury, UK). Duplicate $20 \mathrm{~g}$ samples of these two food components were added to $30 \mathrm{ml}$ water and titrated to $\mathrm{pH} 2$ with $0 \cdot 5 \mathrm{M}-\mathrm{HCl}$, and buffering capacity expressed as mmol $\mathrm{HCl}$ per $400 \mathrm{~g}$ portion.

\section{Statistical analysis}

Data were analysed using SAS version 8.0 (SAS Institute Inc., Cary, NC, USA). ANOVA was performed with a mixed-effect model for a three-period cross-over design, which compared the three conditions (whole carrots, blended carrots, carrot nutrients; Jones \& Kenward, 1989). The model contained condition, period and 'carry-over', a random subject effect and a random error. As stated, subjects were treated as random, and the fixed effects were condition, period and 'carry-over'. The condition effect refers to differences in the mean response of the variables (VAS and timings, and the weight of food and drink, energy, macronutrient, fibre, water and alcohol intakes) between the three conditions, whereas the period effect refers to differences in the mean responses due to systematic differences between the treatment periods.

Analysis showed that the effects of carry-over and period were non-significant. Thus, assuming no carry-over, an $F$ ratio test was conducted for the comparison of significant effects of each variable between conditions (Jones \& Kenward, 1989). To compare specific conditions, linear contrasts were used to examine differences between means. Results were considered significant at $P<0 \cdot 05$. All values are reported as means and standard deviations.

\section{Results}

\section{Subjects}

Subjects were aged 33 (SD 7.03) years (range 21-40 years), with a BMI of 24.4 (SD 4.03 ) $\mathrm{kg} / \mathrm{m}^{2}$ (range $20.9-28.7 \mathrm{~kg} / \mathrm{m}^{2}$ ). Scores from the eating behaviour questionnaire were: restrained eating, 2.76 (SD 0.82) (range 1.11-3.90); emotional eating, 2.55 (SD 0.94) (range 1.08-4.83); external eating, 3.05 (SD 0.49) (range 2.17-4.33). There are no accepted cut-off points for these factors. Green \& Blundell (1996) considered that a score of over 3 indicated a restrained eater, and eight subjects scored between 3 and 4 for restrained eating; in view of the cross-over design, however, these were not excluded from the final analyses

During the study, four subjects withdrew for reasons unrelated to the study. Assuming that the dropout was random, and the missing data were missing completely at random, the dropout process was ignorable (Little \& Rubin, 1987), and thus the data were analysed accordingly for the three conditions (whole carrots, $n$ 34; blended carrots, $n$ 34; carrot nutrients, $n$ 32).

\section{Time-to-eat and hedonic, sensory and satiety responses}

All subjects consumed the complete lunch meal. There were significant differences in the time taken to eat the lunch meals (whole carrots longer than blended carrots longer than carrot nutrients; Table 2). Subjects did not, however, report any significant differences in the perceived size of the three meals. Subjects reported that the meal with blended carrots had a significantly thicker consistency than the meal with carrot nutrients, but this difference was relatively small. Subjects reported enjoying the meals with whole carrots and carrot nutrients significantly more than the meal with blended carrots, but reported differences in pleasantness and sweetness were small and non-significant (Table 2).

Generally, subjects reported feeling significantly less hungry, more full, with lower desire to eat and prospective consumption after consuming the meals with whole and blended carrots compared with the meal with carrot nutrients (Fig. 1). Differences in the satiety ratings between the whole and blended carrots were not significant. The three meals did not induce any significant differences in reported thirst, which had a mean rating of 34.2 before the lunch meal, decreased to a minimum of 26.7 at the first after-meal assessment and gradually increased to a final mean rating of $36 \cdot 8$ (data not shown).

Table 2. Time taken to eat, and hedonic and sensory responses to the lunch meal

(Mean values and standard deviations)

\begin{tabular}{|c|c|c|c|c|c|c|}
\hline & \multicolumn{6}{|c|}{ Condition } \\
\hline & \multicolumn{2}{|c|}{$\begin{array}{l}\text { Whole carrots } \\
\qquad(n \text { 34) }\end{array}$} & \multicolumn{2}{|c|}{$\begin{array}{c}\text { Blended } \\
\text { carrots (n 34) }\end{array}$} & \multicolumn{2}{|c|}{$\begin{array}{l}\text { Carrot nutri- } \\
\text { ents ( } n 32)\end{array}$} \\
\hline & Mean & SD & Mean & SD & Mean & SD \\
\hline $\begin{array}{r}\text { Time taken to } \\
\text { eat (min) }\end{array}$ & $16 \cdot 9^{\mathrm{a}}$ & $3 \cdot 1$ & $12 \cdot 9^{b}$ & 1.5 & $10 \cdot 2^{\mathrm{c}}$ & 1.4 \\
\hline Size & $72 \cdot 9^{a}$ & 3.5 & $71 \cdot 7^{\mathrm{a}}$ & $4 \cdot 4$ & $69 \cdot 7^{a}$ & $6 \cdot 2$ \\
\hline Consistency† & $75 \cdot 2^{\mathrm{ab}}$ & $13 \cdot 0$ & $79 \cdot 2^{a}$ & 11.4 & $72 \cdot 5^{\mathrm{b}}$ & $14 \cdot 2$ \\
\hline Sweetnessł & $53 \cdot 3^{a}$ & $9 \cdot 4$ & $51 \cdot 0^{a}$ & $15 \cdot 5$ & $50 \cdot 1^{a}$ & $15 \cdot 6$ \\
\hline Pleasantness $\ddagger$ & $64 \cdot 3^{a}$ & $25 \cdot 0$ & $63 \cdot 7^{\mathrm{a}}$ & $24 \cdot 6$ & $64 \cdot 6^{a}$ & $24 \cdot 4$ \\
\hline Enjoyment‡ & $70 \cdot 7^{a}$ & $16 \cdot 5$ & $55 \cdot 3^{b}$ & 21.5 & $65 \cdot 7^{a}$ & $24 \cdot 3$ \\
\hline
\end{tabular}

${ }^{a, b, c}$ Mean values within a row with unlike superscript letters were significantly different $(P<0.05, F$ ratio test).

*Anchors for size were on the left (0) 'extremely small' and the right (100) 'extremely large'.

† Anchors for consistency were on the left (0) 'not thick at all' and the right (100) 'extremely thick'.

¥Anchors for sweetness, pleasantness and enjoyment were on the left (0) 'not at all' and the right (100) 'extremely'.

For details of diets and procedures, see p. 588. 


\section{Intake assessments}

The lunch meals provided 39.2 (SD 3.6) \% (range $30 \cdot 3-46 \cdot 1 \%$ ) of the subjects' estimated daily energy requirements and were completely consumed by all subjects. Total energy intakes for the whole day (including breakfast) were 9914 (SD 656) kJ (range 8379-11400 kJ) for the carrot nutrient condition, 8741 (SD 552) kJ (range 7957-10313 kJ) for the blended carrot condition, and 7898 (SD 624) kJ (range 6618$9077 \mathrm{~kJ}$ ) for the whole carrots. Total energy intakes for the whole day, as percentages of estimated daily energy requirements were: carrot nutrients, 116 (SD 12.5) (range 85$145 \%$ ); blended carrots, 103 (SD 11.7) (range 77-130\%); whole carrots 93 (SD 10.6) (range 74-114\%).

There were no significant differences in water intake ad libitum between meals in the morning or in the afternoon (data not shown). Intakes of energy, food, drink,
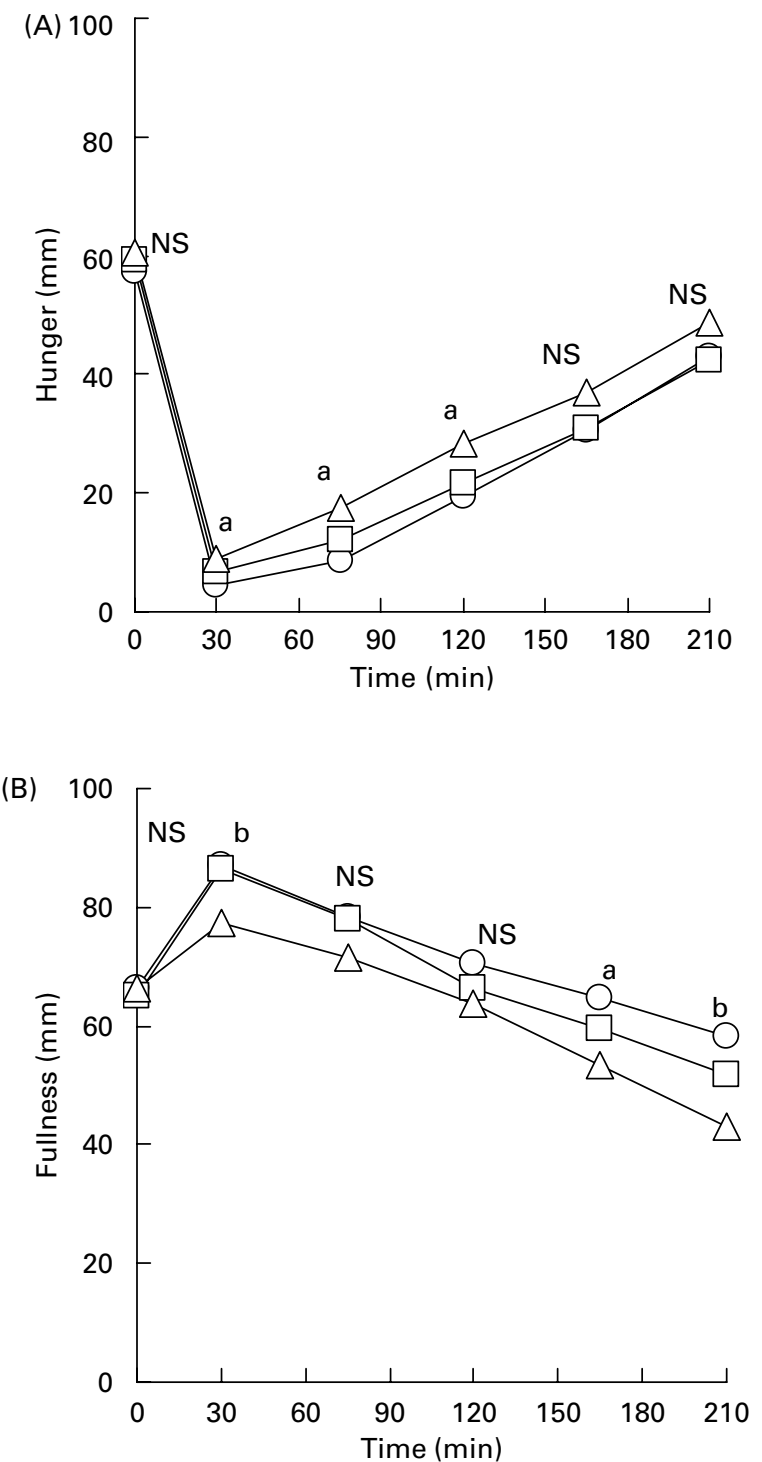

macronutrients, fibre and water at the afternoon meal eaten $a d$ libitum ( $3 \mathrm{~h}$ after the lunch meal) are presented in Table 3. Across the three conditions, these intakes decreased consistently in the order carrot nutrients more than blended carrots more than whole carrots. There were significant differences between the three conditions for intakes of total energy, food energy, carbohydrate and protein. Notably, at the meal eaten ad libitum, compared with the carrot nutrient condition, total energy intakes were $634 \mathrm{~kJ}(22 \%)$ lower following the blended carrots and $1212 \mathrm{~kJ}(42 \%)$ lower following the whole carrots.

Other differences were less well defined, and although intakes of weight of food and drink, weight of food and fibre were significantly greater following the carrot nutrients compared with the blended and whole carrots, the differences between these two conditions were not significant. The intake of fat, and the fat as percentage energy, was significantly less following the whole carrots compared with the other two conditions. Drinks
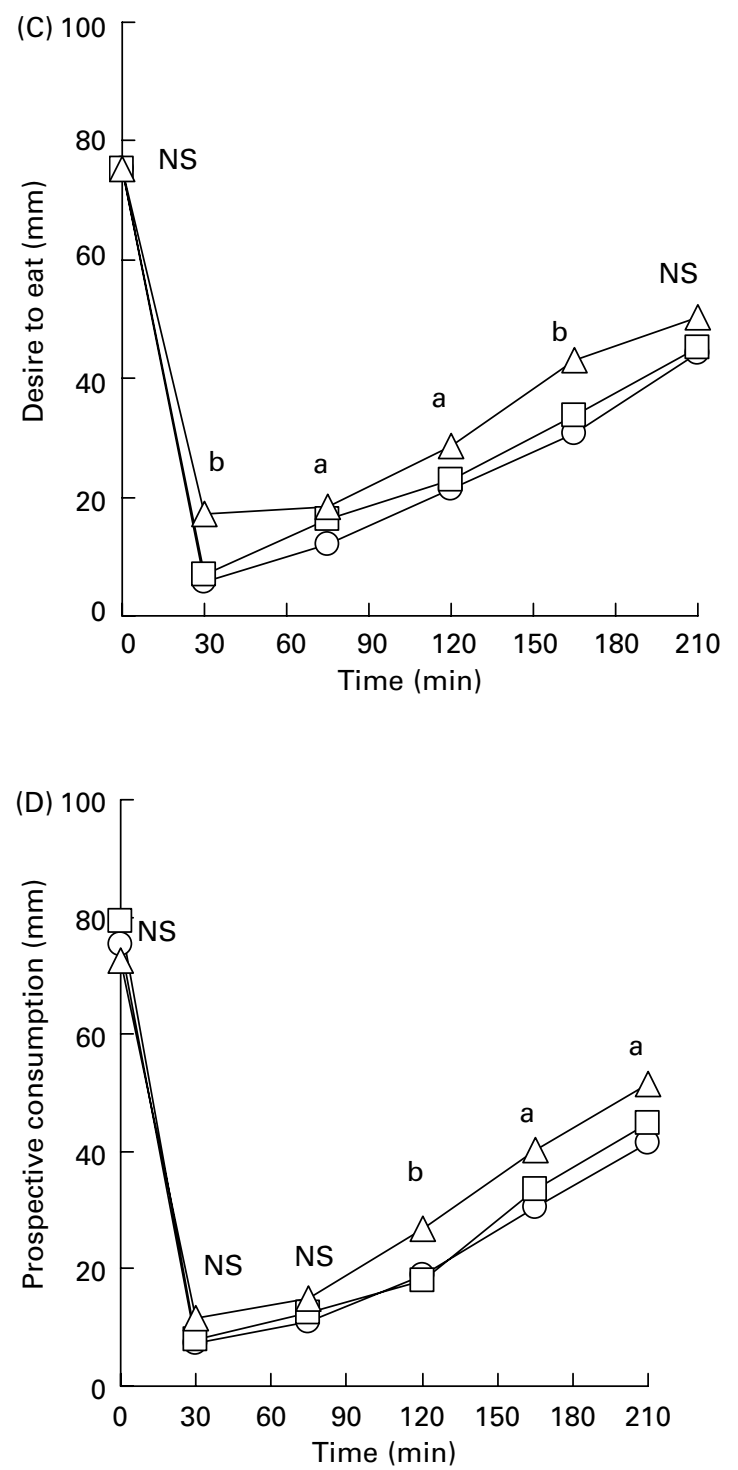

Fig. 1. Visual analogue scale scores of mean subjective ratings of $(A)$ hunger (B) fullness (C) desire to eat, (D) prospective consumption from before the lunch meal until $3 \mathrm{~h}$ after consumption. $\mathrm{O}$, whole carrots; $\square$, blended carrots; $\Delta$, carrot nutrients. ${ }^{\text {a }}$ Significant difference between the meals with the carrot nutrients and the whole carrots $\left(P<0.05, F\right.$ ratio test). ${ }^{b}$ Significant difference between the meal with carrot nutrients and the meals with whole carrots and blended carrots $(P<0.05, F$ ratio test). For details of diets and procedures, see p. 588. 
alone provided only $5-11 \%$ total energy, and there were no significant differences in energy and macronutrient intakes from drink or in intakes of total water or food water.

Reported food, drink, energy, macronutrient, fibre, water and alcohol intakes for the remainder of the day (Table 4) showed a similar general pattern to those found at the afternoon meal eaten ad libitum, with intakes decreasing consistently in the order carrot nutrients more than blended carrots more than whole carrots. Some of these intake differences appeared to be very substantial. However, as might be expected from self-reported data for self-selected diets, CV were much greater than for the meal eaten ad libitum. Consequently, these differences were significant only for intakes of weight of food, total energy, food energy, carbohydrate and fat, which were significantly lower for the whole and blended carrots compared with the carrot nutrient condition, and for protein, which was significantly lower for the whole carrots compared with the other two conditions.

Alcohol consumption was not restricted; six subjects reported alcohol consumption on one study day, and five subjects on two study days.

\section{Laboratory evaluations}

Microscopy showed the presence of copious cell wall fragments on all fields of the blended carrots. No intact cells were, however, observed, indicating that blending had completely disrupted the cell structure. The water activities of the blended carrots in sauce and the carrot nutrients in sauce were the same $(0.89)$, and the respective $\mathrm{pH}$ values $(5.0,4.9)$ and buffering capacities $(95.5,81.0 \mathrm{~mm}-\mathrm{HCl}$ per $400 \mathrm{~g}$ portion) were similar.

\section{Discussion}

The intakes for the remainder of the day were self-reported, and such data are susceptible to misreporting (Black et al. 1993).
The aim was, however, to compare intakes across conditions, and the within-subject cross-over design of the present study enabled valid comparisons to be made. Nevertheless, total energy intakes for the whole day, as percentages of estimated daily energy requirements, were 116 (SD 12.5) (range 85$145 \%$ ) for the carrot nutrient condition, 103 (SD 11.7) (range $77-130 \%$ ) for the blended carrot condition, and 93 (SD 10.6) (range $74-114 \%$ ) for the whole-carrot condition, which indicates that overall energy intakes reflected normal intakes.

The $800 \mathrm{~g}$ lunch meals were large in comparison with recent data from the UK and the USA that give average portion sizes of 288-300 g for a meal of sweet and sour sauce with chicken and rice, and 85-146 g for carrots (Food Standards Agency, $2002 b$; United States Department of Agriculture, Agricultural Research Service, 2005). A large lunch was used because previous studies indicated that large vegetable portions (200$300 \mathrm{~g}$ ) were needed to exert significant effects on satiety (Gustafsson et al. 1993, 1994), and the other components (sauce, chicken, rice) were included at the same level in order to formulate a realistic mixed meal. Nevertheless, the meals, which provided 39.2 (SD 3.6) \% (range 30.3-46.1) \% of the subjects' estimated daily energy intakes, were completely consumed by all subjects, and the total energy content of the meals $(3329 \mathrm{~kJ})$ was within the range of lunch meals evaluated in other satiety studies (approximately 2130-3700 kJ; Burley et al. 1993a,b; Cooling \& Blundell, 1998). The weight of the lunch meals ( $800 \mathrm{~g}$ ) was, however, substantially more than that used in these previous studies, in which weights ranged from 233 to $630 \mathrm{~g}$, and this may have influenced outcomes (see later).

In contrast to the present study, which evaluated solid and semi-solid meal components, most previous studies that have evaluated effects of variations in structure on satiety and intake have been comparisons of meals in which the ratio of solid:liquid was varied (Almiron-Roig et al. 2003). Mealtypes and study designs were, however, very variable, and the relative impacts of solids and liquids on satiety and

Table 3. Intakes at the afternoon meal, 210 min after the lunch meal by condition (Mean values and standard deviations)

\begin{tabular}{|c|c|c|c|c|c|c|}
\hline & \multicolumn{6}{|c|}{ Condition } \\
\hline & \multicolumn{2}{|c|}{$\begin{array}{l}\text { Whole carrots } \\
\qquad(n \text { 34) }\end{array}$} & \multicolumn{2}{|c|}{$\begin{array}{l}\text { Blended carrots } \\
\qquad(n 34)\end{array}$} & \multicolumn{2}{|c|}{$\begin{array}{l}\text { Carrot nutrients } \\
\text { (n 32) }\end{array}$} \\
\hline & Mean & SD & Mean & SD & Mean & SD \\
\hline Food and drink (g) & $494^{a}$ & 96 & $538^{a}$ & 152 & $638^{b}$ & 104 \\
\hline Food $(\mathrm{g})$ & $282^{a}$ & 98 & $308^{a}$ & 126 & $407^{b}$ & 144 \\
\hline Drink (g) & $212^{a}$ & 86 & $230^{a}$ & 86 & $231^{a}$ & 87 \\
\hline Total energy (kJ) & $1669^{a}$ & 489 & $2247^{\mathrm{b}}$ & 904 & $2881^{\mathrm{c}}$ & 778 \\
\hline Food energy (kJ) & $1549^{\mathrm{a}}$ & 471 & $2107^{b}$ & 889 & $2661^{c}$ & 765 \\
\hline Protein $(\mathrm{g})$ & $12 \cdot 5^{a}$ & 4.6 & $16 \cdot 3^{b}$ & 6.6 & $18 \cdot 5^{c}$ & $7 \cdot 0$ \\
\hline As $\%$ total energy & $12 \cdot 6^{\mathrm{a}}$ & $1 \cdot 7$ & $12 \cdot 3^{a}$ & $1 \cdot 8$ & $10 \cdot 9^{a}$ & $2 \cdot 1$ \\
\hline Fat $(g)$ & $17 \cdot 3^{a}$ & 9.9 & $26 \cdot 2^{b}$ & $16 \cdot 1$ & $38.0^{b}$ & 11.4 \\
\hline As $\%$ total energy & $38 \cdot 4^{a}$ & $5 \cdot 6$ & $43 \cdot 2^{b}$ & $5 \cdot 9$ & $48 \cdot 8^{b}$ & $5 \cdot 4$ \\
\hline Carbohydrate (g) & $51 \cdot 0^{\mathrm{a}}$ & $17 \cdot 3$ & $62 \cdot 5^{\mathrm{b}}$ & $22 \cdot 7$ & $72 \cdot 5^{c}$ & $23 \cdot 7$ \\
\hline As $\%$ total energy & $48 \cdot 9^{a}$ & $6 \cdot 0$ & $44 \cdot 5^{a}$ & $5 \cdot 7$ & $40 \cdot 3^{a}$ & $4 \cdot 7$ \\
\hline Fibre (g) & $4 \cdot 3^{a}$ & $1 \cdot 7$ & $5 \cdot 0^{\mathrm{a}}$ & 1.9 & $6 \cdot 0^{\mathrm{b}}$ & 1.9 \\
\hline Total water (g) & $408^{a}$ & 235 & $428^{a}$ & 277 & $503^{a}$ & 296 \\
\hline Food water (g) & $197^{a}$ & 74 & $198^{a}$ & 47 & $272^{a}$ & 68 \\
\hline
\end{tabular}


Table 4. Intakes for the remainder of the day by condition

(Mean values and standard deviations)

\begin{tabular}{|c|c|c|c|c|c|c|}
\hline & \multicolumn{6}{|c|}{ Condition } \\
\hline & \multicolumn{2}{|c|}{$\begin{array}{l}\text { Whole carrots } \\
\qquad(n \text { 34) }\end{array}$} & \multicolumn{2}{|c|}{$\begin{array}{l}\text { Blended carrots } \\
\qquad(n 34)\end{array}$} & \multicolumn{2}{|c|}{$\begin{array}{l}\text { Carrot nutrients } \\
\qquad(n \text { 32) }\end{array}$} \\
\hline & Mean & SD & Mean & SD & Mean & SD \\
\hline Food and drink (g) & $367^{a}$ & 262 & $341^{a}$ & 200 & $449^{a}$ & 328 \\
\hline Food (g) & $88^{a}$ & 269 & $92^{a}$ & 125 & $209^{b}$ & 185 \\
\hline Drink (g) & $279^{a}$ & 130 & $249^{a}$ & 146 & $240^{a}$ & 148 \\
\hline Total energy (kJ) & $756^{a}$ & 323 & $1021^{a}$ & 327 & $1551^{b}$ & 446 \\
\hline Food energy (kJ) & $504^{a}$ & 278 & $784^{a}$ & 281 & $1350^{\mathrm{b}}$ & 379 \\
\hline Protein (g) & $4 \cdot 0^{a}$ & $7 \cdot 6$ & $8 \cdot 2^{b}$ & 7.9 & $10 \cdot 8^{b}$ & $8 \cdot 3$ \\
\hline As $\%$ total energy & $9 \cdot 0^{a}$ & 0.9 & $13 \cdot 7^{a}$ & 1.3 & $11 \cdot 8^{a}$ & 0.6 \\
\hline Fat $(\mathrm{g})$ & $4 \cdot 8^{a}$ & $9 \cdot 4$ & $7 \cdot 7^{\mathrm{a}}$ & $9 \cdot 1$ & $14 \cdot 5^{b}$ & $10 \cdot 7$ \\
\hline As $\%$ total energy & $23 \cdot 5^{a}$ & 1.4 & $27 \cdot 9^{a}$ & 1.9 & $34 \cdot 6^{\mathrm{a}}$ & $2 \cdot 2$ \\
\hline Carbohydrate $(\mathrm{g})$ & $24 \cdot 1^{a}$ & $32 \cdot 3$ & $28 \cdot 2^{a}$ & $21 \cdot 1$ & $48 \cdot 3^{b}$ & 37.5 \\
\hline As $\%$ total energy & $51 \cdot 0^{a}$ & $2 \cdot 7$ & $44 \cdot 2^{a}$ & $2 \cdot 8$ & $49 \cdot 8^{a}$ & 2.9 \\
\hline Alcohol $(g)$ & $4 \cdot 3^{a}$ & $6 \cdot 3$ & $5 \cdot 0^{\mathrm{a}}$ & $6 \cdot 2$ & $2 \cdot 0^{\mathrm{a}}$ & $9 \cdot 0$ \\
\hline As $\%$ total energy & $16 \cdot 5^{a}$ & $1 \cdot 2$ & $14 \cdot 2^{a}$ & 3.6 & $3 \cdot 7^{\mathrm{a}}$ & $5 \cdot 7$ \\
\hline Fibre $(\mathrm{g})$ & $1 \cdot 8^{\mathrm{a}}$ & $3 \cdot 6$ & $1 \cdot 2^{a}$ & 1.5 & $1.9^{\mathrm{a}}$ & $1 \cdot 8$ \\
\hline Total water (g) & $333^{a}$ & 215 & $295^{a}$ & 259 & $373^{a}$ & 274 \\
\hline Food water (g) & $53^{a}$ & 26 & $46^{a}$ & 29 & $134^{a}$ & 46 \\
\hline
\end{tabular}

${ }_{\mathrm{a}, \mathrm{b}}$ Mean values within a row with unlike superscript letters were significantly different $(P<0.05, F$ ratio test). For details of diets and procedures, see p. 588.

intake were influenced by subject characteristics and the size and timings of the meals. An early study showed that meals of intact apple quarters gave greater satiety than apple purée, but this effect may have been partly confounded by a difference in the ratio of solid:liquid in the meals (Haber et al. 1977). In the present study, the carrot nutrient condition resulted in generally lower satiety scores than the whole- and blended-carrot conditions. There were, however, no significant differences in satiety following the whole and blended carrots. This indicated that fibre, but not structure was responsible for the effects on subjective satiety.

The intakes of weight of food, weight of food and drink, energy, macronutrients and fibre were significantly higher following the carrot nutrients than the other two conditions at the meal eaten ad libitum, and these significant differences persisted for the remainder of the day for weight of food, energy and food macronutrients. There were also significant differences in intake between the whole- and blended-carrot conditions for total energy, food energy, protein, fat and carbohydrate intakes at the meal eaten ad libitum. Furthermore, with the exception of the alcohol, fibre and water intakes for the remainder of the day, intakes consistently decreased in the order carrot nutrients more than blended carrots more than whole carrots. Overall, this suggests that both fibre content and structure contributed to the decreased intakes following the consumption of carrots in a mixed meal.

There is considerable evidence that fibre increases satiety and decreases subsequent energy intake (Howarth et al. 2001). We have, however, been able to identify only four previous studies that have evaluated the effects on satiety and/or intake in which the fibre content has been varied in single mixed meals, balanced for weight and macronutrient content as reported here; these are described and compared with the present study.

A comparison of cereal-based breakfasts $(2550-2920 \mathrm{~kJ}$, $460 \mathrm{~g}$ ) with 12.5 or $3 \mathrm{~g}$ fibre showed that higher fibre intake resulted in significantly greater satiety after $60 \mathrm{~min}$, but there were no significant differences in energy intakes at $150 \mathrm{~min}$ (Burley et al. 1987). When $29 \mathrm{~g}$ additional sugar beet fibre was incorporated into a cereal and sausage breakfast (approximately $2900 \mathrm{~kJ}, 447-476 \mathrm{~g}$; baseline fibre not reported), satiety was not significantly affected, but the high-fibre meal led to significantly lower energy intakes $(-14 \%)$ at lunch, and this effect persisted until the next day (Burley et al. 1993a).

A comparison of breakfasts of pasta, hamburger and vegetables (2900-3600 kJ, approximately $625 \mathrm{~g}$ ) with or without fibre depletion (approximately $3 \mathrm{~g} v$. approximately $17 \mathrm{~g}$ fibre) showed that the high-fibre meal led to significantly lower hunger after 120 and $180 \mathrm{~min}$, but intakes were not assessed (Benini et al. 1995). When lunch meals (approximately $3700 \mathrm{~kJ}$ and $625 \mathrm{~g}$ ) of rice and sauce with chicken (3g fibre) or with mycoprotein (13 g fibre) were compared using a design very similar to the present study, the higherfibre meal led to significantly greater satiety at $4-4.5 \mathrm{~h}$, and significantly lower energy intakes $(-18 \%)$ at the evening meal (Burley et al. 1993b).

The latter outcome is similar to the present study using meals of $3329 \mathrm{~kJ}$ and $800 \mathrm{~g}$, in which we found that, compared with the meal with carrot nutrients ( $0.4 \mathrm{~g}$ fibre), the meal with blended carrots ( $4.8 \mathrm{~g}$ fibre) led to significantly greater satiety for up to $3 \mathrm{~h}$ and gave total energy intakes that were $22 \%$ lower at the next meal.

The afore-mentioned comparisons suggest that carrot fibre may be at least as effective as other fibre sources for increasing satiety and decreasing intake, and that these effects are attained with a relatively low dose. In addition to variations in fibre characteristics such as solubility or viscosity profiles, there are, however, a number of other differences between the present study and those outlined earlier, which may have contributed to the differences in the apparent effectiveness of these varying fibre sources in influencing satiety. These include variations in meal weights, the nature of the background meals, the levels of 
fibre in the lower-fibre meals and the range of fibre levels evaluated. For example, a comparison of a large $(5468 \mathrm{~kJ}$, $650 \mathrm{~g})$ or small $(1822 \mathrm{~kJ}, 217 \mathrm{~g})$ solid meal of ground meat and sauce showed that, despite the faster gastric emptying rate of the large meal, a much greater percentage of the large meal was retained in the stomach over the $4 \mathrm{~h}$ of measurement (Doran et al. 1998). This suggests that the use of a large meal $(800 \mathrm{~g})$, as in the present study, may have greater effects on gastric function (see later) than the relatively smaller meals (approximately 450-625 g) evaluated in the previous studies outlined earlier.

Furthermore, the fibre levels used in the present study ( 0.4 and $4.8 \mathrm{~g}$ ) represented a 12 -fold range, compared with 4- to 6fold ranges in the previous studies. It is also worth noting that significant physiological effects, in terms of lowering plasma cholesterol, can be achieved by doses of only $3 \mathrm{~g} / \mathrm{d}$ soluble fibre from oats and other sources (Food and Drug Administration and Department of Health and Human Services, 2002). Taken overall, the results of the present study indicate that carrot fibre is relatively effective at enhancing satiety and lowering subsequent intakes.

Carrot fibre is mainly insoluble cellulose and soluble pectin (Englyst et al. 1988), and these components may have contributed to increased viscosity of the digesta in the stomach and small intestine. This offers putative mechanisms for the effects on satiety and intake since increased meal viscosity can delay gastric emptying and enhance satiety (Marciani et al. 2000; Darwiche et al. 2003), whereas, conversely, the removal of fibre naturally present in food accelerates gastric emptying (Benini et al. 1995). The rate of gastric emptying may also be inversely related to the osmolality, pH or buffering capacity of a meal (Tadesse, 1986; Liljeberg \& Björck, 1996). The blended carrots with sauce, and the carrot nutrients with sauce, were, however, very similar in these respects, indicating that these factors did not contribute to the observed effects. If gastric events are involved, they may not fully account for the persistence of these effects. Increased viscosity of digesta in the small intestine may decrease the rate of digestion and absorption of nutrients, impacting on postprandial glucose and insulin levels and increasing satiety (Pereira \& Ludwig, 2001).

Furthermore, there are a number of hormones secreted by the gut in response to viscous fibre and other stimuli that have putative effects on satiety and that may mediate the responses observed (Howarth et al. 2001; Pereira \& Ludwig, 2001; Drazen \& Woods, 2003; Druce et al. 2004). For example glucagon-like peptide- 1 is a putative satiety hormone secreted not only by the small intestine, but also by the colon (Drazen \& Woods, 2003; Druce et al. 2004), where its secretion may be stimulated by SCFA produced by the bacterial fermentation of fibre (Pereira \& Ludwig, 2001). The decreased energy intakes observed following the meals with the blended carrots or whole carrots were associated with substantial decreases in both total fat intake and the percentage of energy from fat at the meal eaten ad libitum. It is tempting to speculate that this may be a specific effect elicited by satiety hormones (Druce et al. 2004) or other effects in response to fibre (Howarth et al. 2001). Although this remains a possibility, it is more likely to be an artefact as a result of subjects selecting more of the higher-fat food items when total food intakes were increased.
The time taken to eat test meals is recognised as a potential confounding factor in satiety research, and time-to-eat has been standardised in some studies (Haber et al. 1977; Rolls et al. 1998, 2000). In the present study, time-to-eat increased significantly in the order carrot nutrients less than blended carrots less than whole carrots. This is consistent with previous work showing that time-to-eat increased in the order apple juice being less than apple puree being less than intact apples (Haber et al. 1977), and these differences are probably due to the increased time taken in cutting and masticating the structure of the carrots in the whole-carrot meal, and to the thicker consistency of the blended-carrot meal. Subjects in the present study did not, however, report any perceived differences in the size of the meals. Furthermore, it appears unlikely that the 3-7 min longer spent eating the lunches with whole or blended carrots contributed to the decreased intakes observed both at the next meal (approximately $180 \mathrm{~min}$ later) and for the remainder of the day.

The ratings for pleasantness and enjoyment indicated that the three meals were favourably accepted and, although significant in some cases, the differences in hedonic and sensory ratings were small. Subjects were not asked to rate other sensory factors such as saltiness, nor were levels of comfort or nausea assessed. However, no subjects reported any discomfort. Overall, sensory or hedonic factors did not appear to contribute directly to the effects observed.

This study has shown that whole or blended carrots, eaten as part of a mixed lunch meal, result in significantly increased satiety and decreased subsequent intakes. The effects appear to be attributable to both the physical structure and the fibre content of the carrots. Other studies in which test meals have been given at breakfast or lunch have also shown effects on intake that persist well beyond the next meal (Burley et al. 1993b; Rolls et al. 1998; Lawton et al. 2000; Burns et al. 2001). This suggests that the manipulation of a single daily meal to yield enhanced satiety may offer a strategy for decreasing overall energy intake, at least in the short term. Work is needed to further elucidate the mechanisms involved, to evaluate satiety and intake following the consumption of smaller carrot portions and other raw and cooked vegetables, to compare the effects of vegetables with those of added fibre isolates, and to evaluate the potential impact of increased vegetable consumption on body weight.

\section{Acknowledgements}

We thank Dr George McKerr and Dr Barry O'Hagan for help with the microscopy. A preliminary report of this work was given at the Nutrition Society Meeting, Cork, June, 2003 (Proc Nutr Soc 2003; 62, 17A).

\section{References}

Almiron-Roig E, Chen Y \& Drewnowski A (2003) Liquid calories and the failure of satiety: how good is the evidence? Obesity Rev 4, 201-212.

Astrup A, Nielsen CM \& Jebb SA (2004) Are we getting fat from the foods we do not eat? Obesity Rev 5, 89-90.

Benini L, Castellani G, Brighenti F, et al. (1995) Gastric emptying of a solid meal is accelerated by the removal of dietary fibre naturally present in food. Gut 36, 825-830. 
Black AE, Prentice AM, Goldberg GR, Jebb SA, Bingham SA, Livingstone MBE \& Coward WA (1993) Measurements of total energy expenditure provide insights into the validity of dietary measurements of energy intake. J Am Diet Assoc 93, 572-579.

Bolton RP, Heaton KW \& Burroughs LF (1981) The role of dietary fiber in satiety, glucose and insulin: studies with fruit and fruit juice. Am J Clin Nutr 34, 211-217.

Burley VJ, Leeds AR \& Blundell JE (1987) The effect of high and low fibre breakfasts on hunger, satiety and food intake in a subsequent meal. Int $J$ Obes 11, 87-93.

Burley VJ, Paul AW \& Blundell JE (1993a) Sustained post-ingestive action of dietary fibre; effects of a sugar-beet-fibre-supplemented breakfast on satiety. J Hum Nutr Diet 6, 253-260.

Burley VJ, Paul AW \& Blundell JE (1993b) Influence of a high-fibre food (myco-protein) on appetite: effects on satiation (within meals) and satiety (following meals). Eur J Clin Nutr 47, 409-418.

Burns AA, Livingstone MBE, Welch RW, Dunne A, Reid CA \& Rowland IR (2001) The effects of yoghurt containing a novel fat emulsion on energy and macronutrient intakes in non-overweight, overweight and obese subjects. Int J Obes 25, 1487-1496.

Cooling J \& Blundell J (1998) Are high-fat and low-fat consumers distinct phenotypes? Differences in the subjective and behavioral response to energy and nutrient challenges. Eur J Clin Nutr 52, $193-201$.

Darwiche G, Björgell O \& Almér L (2003) The addition of locust bean gum but not water delayed the gastric emptying rate of a nutrient semisolid meal in healthy subjects. BMC Gastroenterology 3, $12-18$.

Department of Health (1997) At Least Five-a-Day Strategies To Increase Vegetable and Fruit Consumption. London: Stationery Office.

Doran S, Jones KL, Andrews JM \& Horowitz M (1998) Effects of meal volume and posture on gastric emptying of solids and appetite. Am J Physiol 275, R1712-R1718.

Drazen DL \& Woods SC (2003) Peripheral signals in the control of satiety and hunger. Curr Opin Clin Nutr Metab Care 6, 621-628.

Druce MR, Small CJ \& Bloom SR (2004) Gut peptides regulating satiety. Endocrinol 145, 2660-2665.

Englyst HN, Bingham SA, Runswick SA, Collinson E \& Cummings JH (1988) Dietary fibre (non-starch polysaccharides) in fruit, vegetables and nuts. J Hum Nutr Diet 1, 247-286.

Food and Drug Administration and Department of Health and Human Services (2002) Food Labeling: Health Claims; Soluble Dietary Fiber From Certain Foods and Coronary Heart Disease. http:// www.cfsan.fda.gov/ 1rd/fr02102b.html (accessed 12 December 2005).

Food Standards Agency (2002a) McCance and Widdowson's The Composition of Foods, 6th ed. Cambridge: Royal Society of Chemistry.

Food Standards Agency (2002b) Food Portion Sizes. London: Stationery Office.

Green SM \& Blundell JE (1996) Effect of fat- and sucrose-containing foods on the size of eating episodes and energy intake in lean dietary restrained and unrestrained females: potential for causing overconsumption. Eur J Clin Nutr 50, 625-635.

Gustafsson K, Asp NG, Hagander B \& Nyman M (1993) Effects of different vegetables in mixed meals on glucose homeostasis and satiety. Eur J Clin Nutr 47, 192-200.

Gustafsson K, Asp NG, Hagander B \& Nyman M (1994) Doseresponse effects of boiled carrots and effects of carrots in lactic acid in mixed meals on glycaemic response and satiety. Eur $J$ Clin Nutr 48, 368-396.

Haber GB, Heaton KW \& Murphy D (1977) Depletion and disruption of dietary fibre: effects on satiety, plasma-glucose, and serum-insulin. Lancet ii, 679-682.

Holt S, Brand Miller JC, Petocz P \& Farmakalidis E (1995) Satiety index of common foods. Eur J Clin Nutr 49, 675-690.

Howarth NC, Saltzman E \& Roberts SB (2001) Dietary fibre and weight regulation. Nutr Rev 59, 129-139.

Jones B \& Kenward MG (1989) Design and Analysis of Cross-over Trials. London: Chapman \& Hall.

Lawton CL, Delargy HJ, Brockman J, Smith FC \& Blundell JE (2000) The degree of saturation of fatty acids influences postingestive satiety. Br J Nutr 83, 473-482.

Liljeberg HGM \& Björck IME (1996) Delayed gastric emptying rate as a potential mechanism for lowered glycemia after eating sourdough bread: studies in human and rats using test products with added organic acids or an organic salt. Am J Clin Nutr 64, 886-893.

Lissner L, Stevens J, Levitsky DA, Rasmussen KM \& Strupp BJ (1988) Variation in energy intake during the menstrual cycle: implications for food-intake research. Am J Clin Nutr $\mathbf{4 8}$, 956-962.

Little RJA \& Rubin DB (1987) Statistical Analysis with Missing Data. New York: Wiley.

Marciani L, Gowland PA, Spiller RC, Manoj P, Moore RJ, Young P, AlSahab S, Bush D, Wright J \& Fillery-Travis AJ (2000) Gastric response to increased meal viscosity assessed by echo-planar magnetic resonance imaging in humans. J Nutr 130, 122-127.

Pereira MA \& Ludwig DS (2001) Dietary fiber and body-weight regulation: observations and mechanisms. Pediatr Clin North Am 48, 969-980.

Rolls BJ, Bell EA \& Thorwart ML (1999) Water incorporated into a food but not served with a food decreases energy intake in lean women. Am J Clin Nutr 7, 448-455.

Rolls BJ, Bell EA \& Waugh BA (2000) Increasing the volume of a food by incorporating air affects satiety in men. Am J Clin Nutr 72, 361-368

Rolls BJ, Castellanos VH, Halford JC, Kilara A, Panyam D, Pelkman CL, Smith GP \& Thorwart ML (1998) Volume of food consumed affects satiety in men. Am J Clin Nutr 67, 1170-1177.

Rolls BJ, Ello-Martin JA \& Tohill BC (2004) What can intervention studies tell us about the relationship between fruit and vegetable consumption and weight management? Nutr Rev 62, 1-17.

Schofield WN (1985) Predicting basal metabolic rate, new standards and review of previous work. Hum Nutr: Clin Nutr 39C, 5-41.

Tadesse K (1986) The effect of dietary fibre isolates on gastric secretion, acidity and emptying. Brit J Nutr 55, 507-513.

United States Department of Agriculture, Agricultural Research Service (2005) USDA National Nutrient Database for Standard Reference, Release 17. http://www.nal.usda.gov/(accessed 10 June 2005).

United States Department of Health and Human Services and United States Department of Agriculture (2005) Dietary Guidelines for Americans. http://www.health.gov/dietaryguidelines (accessed 10 June 2005).

van Strien T, Frijters JER, Bergers GPA \& Defares PB (1986) The Dutch eating behaviour questionnaire (DEBQ) for assessment of restrained, emotional, and external eating behaviour. Int J Eating Disord 5, 295-315. 